\title{
Automatic Segmentation of Impaired Joint Space Area for Osteoarthritis Knee on X-ray Image using Gabor Filter Based Morphology Process
}

\author{
Lilik Anifah $^{1}$, I Ketut Eddy Purnama ${ }^{2}$, Moch. Hariadi $^{2}$, and Mauridhi Hery Purnomo ${ }^{2}$
}

\begin{abstract}
Segmentation is the first step in osteoarthritis classification. Manual selection is time-consuming, tedious, and expensive. The system is designed to help medical doctors to determine the region of interest of visual characteristics found in knee Osteoarthritis (OA). We propose a fully automatic method without human interaction to segment Junction Space Area (JSA) for OA classification on impaired x-ray image. In this proposed system, right and left knee detection is performed using using Contrast-Limited Adaptive Histogram Equalization (CLAHE) and template macthing. The row sum graph and moment methods are used to segment the junction space area of knee. Overall we evaluated 98 kneess of patients. Experimental results demonstrate an accuracy of the system of up to $100 \%$ for detection of both left and right knee and for junction space detection an accuracy $84.38 \%$ for the right knee and $85.42 \%$ for the left. The second experiment using gabor filter with parameter $\alpha=8, \theta=0, \Psi=[0, \Pi / 2], \gamma=0,8$ and $N=8$ and row sum graph give an accuracy $92.63 \%$ for the right knee and $87.37 \%$ for the left. And the average time needs to process is 65.79 second. For obvious reasons we chose the results of the fourth to segment junction area in both right and the left knee.
\end{abstract}

Keywords — knee osteoarthritis, segmentation, joint space width, CLAHE, gabor filter

Abstrak-Segmentasi image adalah tahap pertama dalam proses klasifikasi osteoarhtritis. Segmentasi manual memerlukan waktu yang lebih banyak serta memerlukan biaya yang lebih mahal. Sistem yang didesain ini diperuntukkan untuk membantu dokter menentukan region of interest pada penyakit osteoarthritis pada bagian lutut. Penelitian ini merekomendasikan metode untuk menentukan Junction Space Area (JSA) tanpa interaksi manusia untuk image $x$-ray. Kami mengusulkan penggunaan metode Contrast-limited adaptive histogram equalization (CLAHE) dan template matching untuk mensegmentasi kaki kanan dan kiri. Kombinasi metode Row sum graph, moment dan Gabor Kernel digunakan untuk mensegmentasi Junction Space Area (JSA) pada lutut. Seacara keseluruhan kami mengevaluasi 98 lutut pasien. Hasil eksperimen menunjukkan bahwa untuk mendeteksi kaki kanan dan kiri mempunyai akurasi 100\%, sedangkan kemampuan untuk mensegmentasi Junction Space Area (JSA) untu kaki kanan dan kiri adalah 84,38\% dan 85,42\%. Untuk percobaan kedua kami menggunakan kombinasi Row sum graph, moment dan Gabor Kernel dengan nilai parameter $\alpha=8, \theta=0, \Psi=[0 \Pi / 2], \gamma=0,8$ dan $N=8$ menghasilkan akurasi 92,63\% untuk lutut kanan dan 87,37\% untuk lutut kiri. Rata-rata waktu yang diperlukan selama proses adalah 65,79 second.

Kata Kunci-knee osteoarthritis, segmentation, joint space width, CLAHE, gabor filter

\section{INTRODUCTION}

$\mathrm{T}_{\mathrm{i}}^{\mathrm{s}}$ he number of people with osteoarthritis in Indonesia is very large 17.533.304 in the year 2004 [1]. Osteoarthritis (OA), the most common joint disorder, comprises a heterogeneous group of syndromes that affect all joint tissues, although the articular cartilage and the adjacent bone often show the most prominent changes. OA represents a leading musculoskeletal health and socioeconomic burden for society worldwide, causing progressive and irreversible articular cartilage tissue damage and, finally, the failure of the joint as a whole organ [2-4].

X-ray, Magnetic Resonance Imaging (MRI) and arthroscopy are the methods most widely used to assess the status of osteoarthritic joints [5]. Some cases were measured by osteo CT [6]. However, in Indonesia it is common to use X-ray or Magnetic Resonance Imaging (MRI).

Lilik Anifah is with Department of Electrical Engineering, Universitas Negeri Surabaya, Indonesia.Email: Anifahl@yahoo.com.

I Ketut Eddy Purnama, Mochamad Hariadi, and Mauridhi Hery Purnomo are with Department of Electrical Engineering, FTI, Institut Teknologi Sepuluh Nopember, Surabaya, 60111, Indonesia. Email: ketut@ee.its.ac.id, mochar@ee.its.ac.id, hery@ee.its.ac.id.
Segmentation is the first step in osteoarthritis classification. Manual selection is time-consuming, tedious, and expensive. Even if a radiologist expert or highly trained person is available to select regions, high inter- and intra-ob-server variabilities are still possible [7]. Our ultimate goal is to develop a fully automated system for osteoarthritis classification. Detection and segmentation of joint space area is a component of the automated system that is currently developed. In this study, we propose an automated method for segmentation of the impaired joint space area for knee.

Several methods have been applied to segment knee junction space area of radiograph image, e.g., using a fixed set of 20 pre-selected images, such that each image is a $150 \times 150$ window of a center of a joint, Finding the joint in a given knee $\mathrm{X}$-ray image is performed by first downscaling the image by a factor 10 , and then scanning the image with a $15 \times 15$ shifted window. For each position, the Euclidean distances between the $15 \times 15$ pixels of the shifted window and each of the $15 \times 15$ predefined joint images [8], developed method consists of image preprocessing, delineation of cortical bone plates 
(active shape model), and location of regions of interest (ROI) [7], ROI detection is performed using edge based segmentation method. The feature to be extracted is the distance between femur and tibia bone by rotated image, array of mean intensity, the parameter rotation, horizontally translated image and vertically translated image [9]. However this method is exactly implemented in X-ray images of healthy knees but not of impaired knees.

We propose a machine vision system for segmentation of joint space area that could be implemented on X-ray images of healthy and impaired knees, using ContrastLimited Adaptive Histogram Equalization (CLAHE), template matching using Euclidean distance measures, the row-sum graph and center-of-mass computation.

This journal is outlined as follows: In section 2 we briefly describe material and the proposed method. Experimental results and discussions will be presented in section 3, followed by discussions in section 4, conclusions in section 5, and future work in section 6 .

\section{METHOD}

\section{A. Material}

We observed 98 x-ray impaired images data obtained from the Osteoarthritis Initiave (OAI) dataset [10]. The fixed-flexion knee X-rays were acquired with the beam angle at 10 degrees. The anterior wall of the SynaFlexer positioning frame (provided by Synarc) must be in direct contact with the bucky, cassette holder or reclining table top of the radiographic unit such that there is no angle or gap between them. To ensure these requirements, the bucky or cassette holder is lowered so that the center of the film will be at the level of the participant's tibiofemoral joint line. The center line of the positioning frame is set to the center of the bucky or cassette holder [11].

Hardware specification used in this research is Dell Inspiron N3010 with Processor Intel(R) Core(TM) i5 CPU M430 @2,27 GHz installed memory (RAM) 2,00 GB.

\section{B. Method}

We divide the experiment into two stages. The first stage to segment the right knee and the left. And the second stage to find the junction space area of the knee.

Digital radiographs were normalized into $2828 \times 2320$ image before segmented. To segment the right and the left knee there are 4 experiments. The first experiment uses only center of mass, the second experiment uses only template matching, the third experiment uses CLAHE and template matching, and the fourth experiment combines CLAHE, template matching, and and center of mass calculation.

The second stage experiment (the segmentation of junction space area) there are 2 experiments. The first experiment row sum graph and center of mass method and the second experiment uses combine gabor filter, row sum graph and center of mass method. The step of this research is figured in Figure 1.
1. Contrast-limited adaptive histogram equalization

Contrast Limited Adaptive Histogram Equalization, CLAHE, is an improved version of AHE, or Adaptive Histogram Equalization. Both overcome the limitations of standard histogram equalization. [12]. CLAHE is a special case of the histogram equalization technique [13].

The procedure of CLAHE technique is described below:

Step 1: Each cell-image was divided into a number of non-overlapping contextual regions of equal sizes, experimentally set to be $2 \times 2$, which corresponds to approximately 40 pixels.

Step 2: The histogram of each contextual region was calculated.

Step 3: A clip limit, for clipping histograms, was set $(\mathrm{t}=0.001)$. The clip limit was a threshold parameter by which the contrast of the cell-image could be effectively altered; a higher clip limit increased cell-spot contrast.

Step 4: Each histogram was redistributed in such a way that its height did not exceed the clip limit.

Step 5: All histograms were modified by the transformation function is the probability density function of the input image grayscale value $j, n$ is the total number of pixels in the input image and $n_{j}$ is the input pixel number of grayscale value $\mathrm{j}$.

Step 6: The neighboring tiles were combined using bilinear interpolation and the cell-image grayscale values were altered according to the modified histograms [14].

Histogram equalization maps the input image's intensity values so that the histogram of the resulting image will have an approximately uniform distribution [15].

The histogram of a digital image with gray levels in the range $[0, L-1]$ is a discrete function

$\mathrm{p}\left(r_{k}\right)=n_{k} / n$

where $r_{k}$ is the kth gray level, $n_{k}$ is the number of pixels in the image with that gray level, $n$ is the total number of pixels in the image, and $k=0,1,2, \ldots, L-1$. Basically $\mathrm{p}\left(r_{k}\right)$ gives an estimate of the probability of occurrence of gray level $r_{k}[16]$

\section{Template Matching using Euclidean distance}

Template Matching is the simplest and the oldest method. It represented by the inner product which is mathematically simple procedure. Template matching can be extended naturally in terms of its mathematical structure to subspace method and also feature matching [17].

Finding position right knee and left knee in a given knee X-ray image is performed by first downscaling the $2828 \times 2320$ image by a factor 30 , i.e.,

$\mathrm{x}^{\prime}=\operatorname{round}(\mathrm{x} / \mathrm{m})$

$\mathrm{y}^{\prime}=$ round $(\mathrm{y} / \mathrm{m})$

where $m=30$ is scale factor, $x^{\prime}$ is scaled width is $y^{\prime}$ is scaled height, $\mathrm{x}$ is width of the image and $\mathrm{y}$ is height of the image.

For right knee the scanning proceeds from $x^{\prime}=1$ to $x^{\prime}=18$ and $y^{\prime}=1$ to $y^{\prime}=20$ and left knee the scanning goes from $x^{\prime}=47$ to $x^{\prime}=64$ and $y^{\prime}=1$ to $y^{\prime}=20$. Each position the Euclidean distances between the $30 \times 57$ pixels are computed as

$d_{i, w}=\sqrt{\sum \sum\left(I_{x^{\prime}, y^{\prime}}-W_{x, y}\right)^{2}}$

where $W_{x, y}$ is the intensity of pixel $\mathrm{x}, \mathrm{y}$ in the shifted window $W, I_{x^{\prime}, y^{\prime}}$ is the intensity of pixel $x^{\prime}, y^{\prime}$ in the 
image $I$, and $d_{i, w}$ is the Euclidean distance between the joint image $I$ and the $30 \times 57$ shifted window $W$.

This simple and fast method was able to successfully find the position right knee and left knee in all images in the dataset. Then we multiply the position with the scale factor.

$x=\operatorname{round}\left(x^{\prime *} m\right)$

$y=\operatorname{round}\left(y^{\prime *} m\right)$

After finding the rescaled template position, we determine its center of mass coordinates $x_{c}=M_{1,0} / M_{0,0}$ and $y_{c}=M_{0,1} / M_{0,0}$ with

$M_{i, j}=\iint x^{i} y^{j} d x d y$

where $M_{i, j}$ is moment of order $i, j$.

3. Row sum graph

Once the knees have been located, we use row sum graphs to determine the junction area. The sum graph represents the row-wise summation of the gray values [18]. Let us consider that our input image be $F(i, j)$, the row sum graph $S(i, j)$ is given by

$S(j)=\sum_{j=1}^{N} F(i, j)$

\section{Grey level centre of mass}

We also determine the center of mass, in terms of gray level in the segmented knee area, to determine the junction area, using the same approach as before, but replacing the binary moment of (7) the gray level counterpart

$M_{i, j}=\iint x^{i} y^{j} f(x, y) d x d y$

\section{Gabor Filter}

The formula of complex Gabor function in space domain is given by

$$
g(x, y)=s(x, y) w_{r}(x, y)
$$

where $s(x, y)$ is a complex sinusoid, known carrier, and $w_{r}(x, y)$ is 2 dimension gaussian-shaped function, known envelope. The complex sinusoid is defined as follows,

$$
s(x, y)=\exp \left(j\left(2 \prod\left(u_{0} x+v_{0} y\right)+P\right)\right)
$$

where $\left(u_{0}, v_{0}\right)$ and $\mathrm{P}$ define the spatial frequency and the phase of the sinusoid respectively.

The gaussian envelope as follows,

$$
w_{r}(x, y)=K \exp \left(-\prod\left(a^{2}\left(x-x_{0}\right)_{r}^{2}+b^{2}\left(y-y_{0} ?\right)_{r}^{2}\right)\right.
$$

where $\mathrm{K}$ is scales the magnitude of gaussian envelope, $(\mathrm{x} 0, \mathrm{y} 0)$ is the peak of the function, $\mathrm{a}$ and $\mathrm{b}$ are scalling parameter of the gaussian. And the $r$ subscript stand for rotation operator [19].

\section{RESULT AND DISCUSSION}

At present, we have developed techniques to perform joint space area automated segmentation and calculation which is necessary for osteoarthritis classification. The segmentation algorithm has been successfully implemented.

\section{A. The First Stage: to Segment the Right Knee and the Left}

The first experiment uses only center of mass. For right knee the scanning proceeds from $x^{\prime}=1$ to $x^{\prime}=1400$ and $y^{\prime}=1$ to $y^{\prime}=2320$ and left knee the scanning goes from $\mathrm{x}^{\prime}=1400$ to $\mathrm{x}^{\prime}=2828$ and $\mathrm{y}^{\prime}=1$ to $\mathrm{y}^{\prime}=2320$. We determine its center of mass coordinates $x_{c}=M_{1,0} / M_{0,0}$ and $y_{c}=M_{0,1} / M_{0,0}$ with

$M_{i, j}=\iint x^{i} y^{j} d x d y$

where $x_{c}$ is the center of horizontal mass, $y_{c}$ is the center of vertical mass, and $M_{i, j}$ moment of the image. The successful result figured in Figure 2 and not successful result figured in Figure 3 and Figure 4.

The second experiment uses only template matching. Finding position right knee and left knee in a given the $2828 \times 2320$ knee X-ray image. For right knee the scanning proceeds from $x^{\prime}=1$ to $x^{\prime}=1920$ and $y^{\prime}=1$ to $y^{\prime}=600$ and left knee the scanning goes from $x^{\prime}=1$ to $x^{\prime}=1920$ and $y^{\prime}=1$ to $y^{\prime}=600$. Each position the Euclidean distances between the $900 \times 1710$ pixels are computed as

$d_{i, w}=\sqrt{\sum \sum\left(I_{x^{\prime}, y^{\prime}}-W_{x, y}\right)^{2}}$

where $W_{x, y}$ is the intensity of pixel $\mathrm{x}, \mathrm{y}$ in the shifted window $W, I_{x^{\prime}, y^{\prime}}$ is the intensity of pixel $x^{\prime}, y^{\prime}$ in the image $I$, and $d_{i, w}$ is the Euclidean distance between the joint image $I$ and the $900 \times 1710$ shifted window $W$. Fig 5 is the successful result of this experiment. Figure 6 and 7 are not successful ones.

The third experiment uses CLAHE and template matching. Before segmented, digital radiographs were normalized into $2828 \times 2320$ image then preprocessed using Contrast-Limited Adaptive Histogram Equalization (CLAHE). CLAHE is a refinement of adaptive histogram equalization [20]. Histogram equalization maps the input image's intensity values so that the histogram of the resulting image will have an approximately uniform distribution [21].

The histogram of a digital image with gray levels in the range $[0, L-1]$ is a discrete function

$\mathrm{p}\left(r_{k}\right)=n_{k} / n$

where $r_{k}$ is the kth gray level, $n_{k}$ is the number of pixels in the image with that gray level, $n$ is the total number of pixels in the image, and $k=0,1,2, \ldots, L-1$. Basically $\mathrm{p}\left(r_{k}\right)$ gives an estimate of the probability of occurrence of gray level $r k$. Figure 8 shows the example of original radiograph and the result of preprocessing and Figure 9 is the histogram of the example of original radiograph and the result of preprocessing. Figure 10 is the successful result and Figure 11 is not successful one.

The fourth experiment combines CLAHE, template matching, and center of mass calculation. Finding position right knee and left knee in a given knee X-ray image is performed by first downscaling the $2828 \times 2320$ image by a factor 30 , i.e.,

$\mathrm{x}^{\prime}=\operatorname{round}(\mathrm{x} / \mathrm{m})$

$\mathrm{y}^{\prime}=\operatorname{round}(\mathrm{y} / \mathrm{m})$

where $m=30$ is scale factor, $x^{\prime}$ is scaled width is $y^{\prime}$ is scaled height, $\mathrm{x}$ is width of the image and $\mathrm{y}$ is height of the image. We then scan the image with a $30 \times 57$ shifted window shown in Figure 12.

For right knee the scanning proceeds from $x^{\prime}=1$ to $x^{\prime}=18$ and $y^{\prime}=1$ to $y^{\prime}=20$ and left knee the scanning goes from $x^{\prime}=47$ to $x^{\prime}=64$ and $y^{\prime}=1$ to $y^{\prime}=20$. Each position the Euclidean distances between the $30 \times 57$ pixels are computed as:

$d_{i, w}=\sqrt{\sum \sum\left(I_{x^{\prime}, y^{\prime}}-W_{x, y}\right)^{2}}$

where $W_{x, y}$ is the intensity of pixel $\mathrm{x}, \mathrm{y}$ in the shifted window $W, I_{x^{\prime}, y^{\prime}}$ is the intensity of pixel $x^{\prime}, y^{\prime}$ in the 
image $\mathrm{I}$, and $\mathrm{d}_{\mathrm{i}, \mathrm{w}}$ is the Euclidean distance between the joint image $I$ and the $30 \times 57$ shifted window $W$.

This simple and fast method was able to successfully find the position right knee and left knee in all images in the dataset. Then we multiply the position with the scale factor.

$x=\operatorname{round}\left(x^{\prime} * m\right)$

$y=\operatorname{round}\left(y^{\prime *} m\right)$

After finding the rescaled template position, we determine its center of mass coordinates $x_{c}=M_{1,0} / M_{0,0}$ and $y_{c}=M_{0,1} / M_{0,0}$ with.

$M_{i, j}=\iint x^{i} y^{j} d x d y$

where $M_{i, j}$ is moment of order $i, j$. The result of the segmentation is shown in Figure 13. Fig (a) is the segmentation of right knee and (b) is the left knee.

\section{B. The Second Stage Experiment (the Segmentation of Junction Space Area)}

Once the knees have been located, we use row sum graphs to determine the junction area. The sum graph represents the row-wise summation of the gray values [16]. Let us consider that our input image be $F(i, j)$, the row sum graph $S(i j)$ is given by

$$
S(j)=\sum_{j=1}^{N} F(i, j)
$$

Figure 14(a) shows the row sum graph of the right knee and Figure 15(a) the row sum graph of the left knee. The minimum of the graph is the junction space area of knee.

We also determine the center of mass, in terms of gray level in the segmented knee area, to determine the junction area, using the same approach as before, but replacing the binary moment of (5) the gray level counterpart

$M_{i, j}=\iint x^{i} y^{j} f(x, y) d x d y$

Figure 14(c) is the result of right knee junction space area segmentation Figure 15(c) is the result of right knee junction space area segmentation.

The formula of complex Gabor function in space domain is given by

$g(x, y)=s(x, y) w_{r}(x, y)$

where $s(x, y)$ is a complex sinusoid, known carrier, and $w_{r}(x, y)$ is 2 dimension gaussian-shaped function, known envelope. The complex sinusoid is defined as follows, $s(x, y)=\exp \left(j\left(2 \prod\left(u_{0} x+v_{0} y\right)+P\right)\right)$

where $\left(u_{0}, v_{0}\right)$ and $\mathrm{P}$ define the spatial frequency and the phase of the sinusoid respectively.

The gaussian envelope as follows,

$w_{r}(x, y)=K \exp \left(-\prod\left(a^{2}\left(x-x_{0}\right)_{r}^{2}+b^{2}\left(y-y_{0} ?\right)_{r}^{2}\right)\right.$

where $\mathrm{K}$ is scales the magnitude of gaussian envelope, $\left(\mathrm{x}_{0}, \mathrm{y}_{0}\right)$ is the peak of the function, $\mathrm{a}$ and $\mathrm{b}$ are scalling parameter of the gaussian. $r$ subscript stand for rotation operator [17].

At present, we have developed techniques to perform joint space area automated segmentation and calculation which is necessary for osteoarthritis classification. The segmentation algorithm has been successfully implemented. The system's accuracy of each stage is shown in Table 1.

Experiment 4 give accuracy $100 \%$ for both knee because it used combine techniques used Experiment 1, 2 and 3 . The first experiment uses only center of mass, it give $95.83 \%$ for right knee and $86.46 \%$ for the left. The second experiment uses only template matching give accuracy $83.33 \%$ and $60.43 \%$, limitation of this method in some cases the region of interest could be twist. The third experiment uses CLAHE and template matching give accuracy $89.58 \%$ and $83.33 \%$ for the left, weakness of this experiment are the speed and some cases the region of interest still could be twist although the intensity had normalized by CLAHE. Fourth experiment combines CLAHE, template matching, and center of mass calculation for finding position right knee and left knee using downscalling method. CLAHE used for normalized the intensity, template matching used for finding the region of interest, and center of mass is solution to minimize possibility twist between the right and the left. The fourth experiment give accuracy $100 \%$ for both knee. Speed is faster then experiment 1, 2, 1nd 3 because for finding position right knee and left knee using downscalling the $2828 \times 2320$ image by a factor 30 . After finding the position, we multiply the position with the scale factor then we determine its center of mass coordinates.

The second stage experiment (the segmentation of junction space area) using row sum graph and center of mass method give an accuracy $84.38 \%$ for the right knee and $85.42 \%$ for the left. And the average time needs to process is 1.404 second. The second experiment using gabor filter with parameter $\alpha=8, \theta=0, \psi=[0 \pi / 2], \gamma=0,8$ and $n=8$ and row sum graph give an accuracy $92.63 \%$ for the right knee and $87.37 \%$ for the left. And the average time needs to process is 65.79 second. For accuracy and speed reasons we chose the results of the fourth to segment junction area in both right and the left knee.

Segmentation is the first step in osteoarthritis classification. We propose a fully automatic method to segment junction space area for OA classification on impaired X-ray image. Future plans we develop fully automatic technique to classify knee $\mathrm{X}$-rays using expert system.

\section{CONCLUSION}

In this reearch, the proposed technique is an effective junction space area segmentation method without the need for user interaction. Experimental results have been provided to show the effectiveness of the proposed technique. And could help medical doctors to determine the region of interest of visual characteristics found in knee OA. The failures in junction detection may well be due to deviations of the angle of the knee joint from the horizontal. We will improve this by including gradient information in the junction area segmentation.

\section{ACKNOWLEDGMENT}

This research was supported by Osteoarthritis Initiative (OAI) USA 


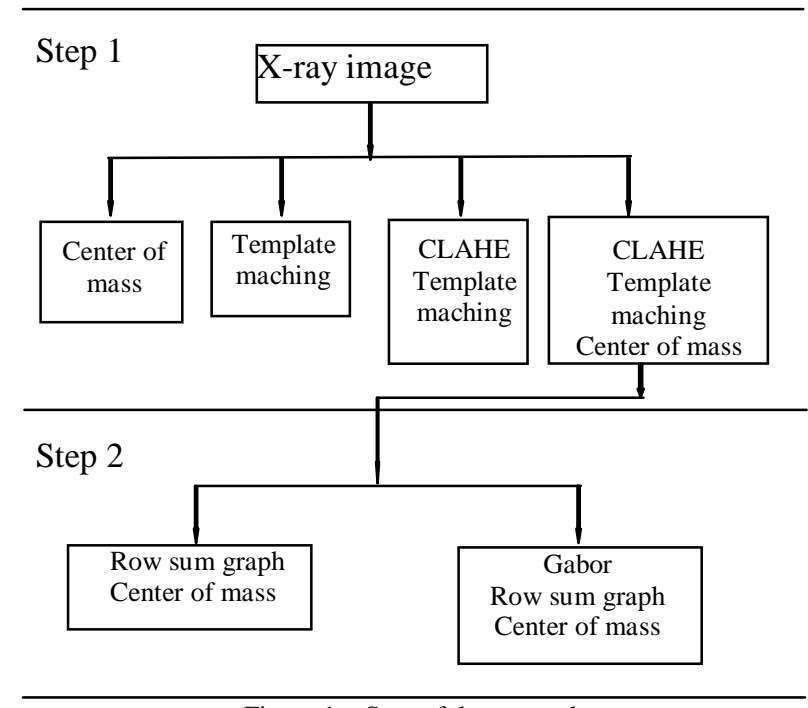

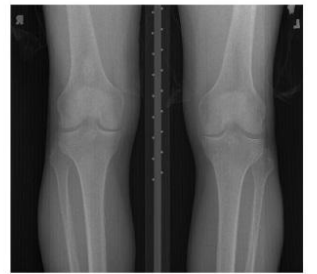

(a)

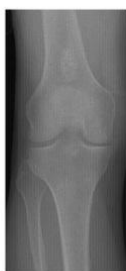

(b)

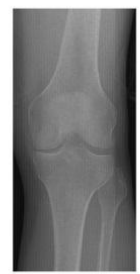

(c)

Figure 2. (a) The original radiograph, (b) right knee segmentation, and (c) left knee segmentation

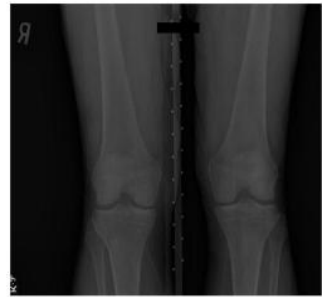

(a)

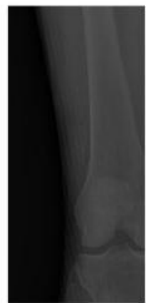

(b)

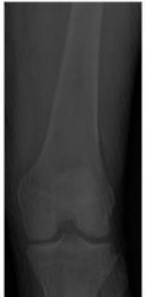

(c)

Figure 4. (a) the original radiograph (b) right knee segmentation (c) left knee segmentation

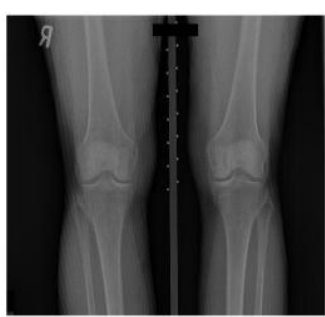

(a)

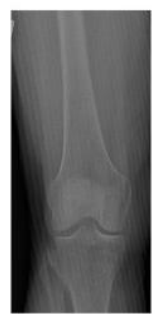

(b)

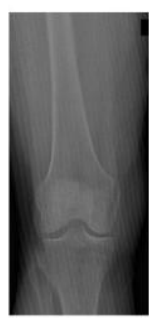

(c)

Figure 6. (a) the original radiograph (b) right knee segmentation (c) left knee segmentation

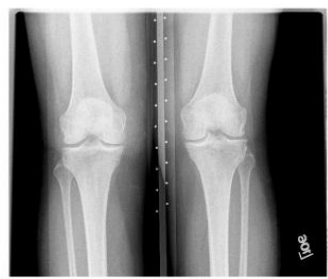

(a)

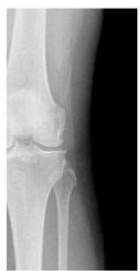

(b)

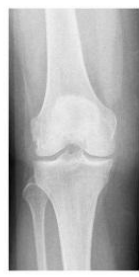

(c)

Figure 3. (a) the original radiograph, (b) right knee segmentation (c) left knee segmentation

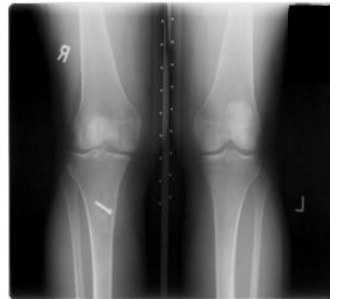

(a)

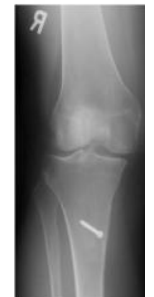

(b)

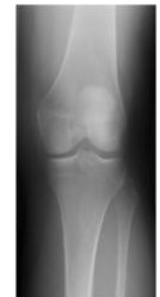

(c)

Figure 5. (a) the original radiograph (b) right knee segmentation (c) left knee segmentation

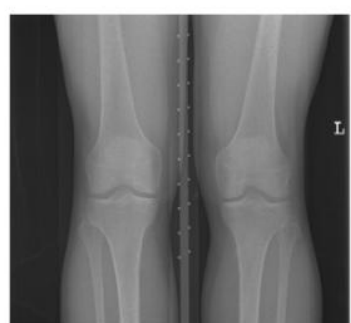

(a)

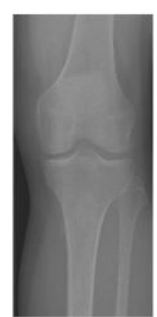

(b)

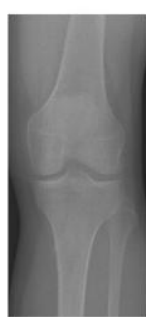

(c)

Figure 7. (a) the original radiograph (b) right knee segmentation (c) left knee segmentation 


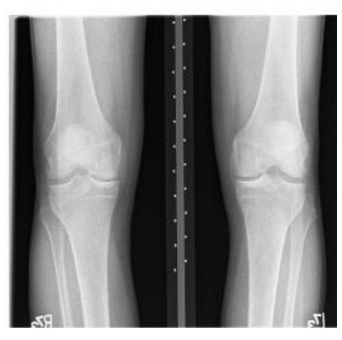

(a)

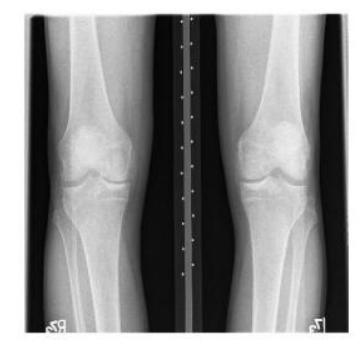

(b)

Figure 8. Comparison of (a) the original radiograph and (b) the result of the processing
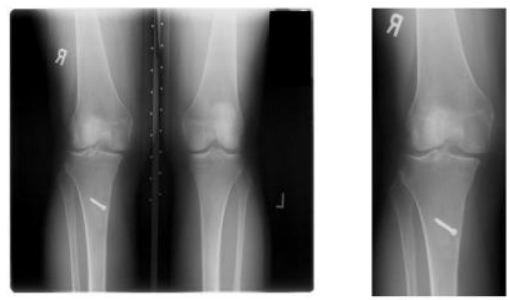

(a)

\begin{abstract}
(b)
\end{abstract}

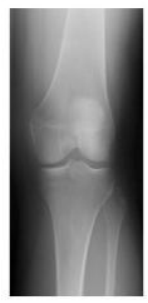

(c)

Figure 10. (a) preprocessed image (b) right knee segmentation (c) left knee segmentation

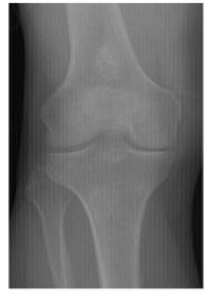

(a)

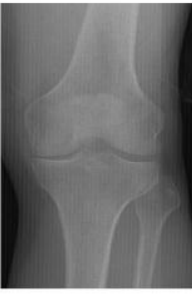

(b)
Fig 12. A $30 \times 57$ shifted window used for finding the position of (a) left knee (b) right knee

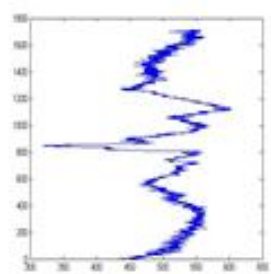

(a)

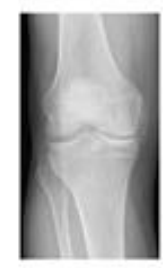

(b)

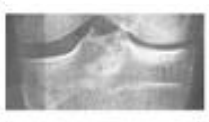

(c)
Figure 14. (a) Row sum graph of right knee (b) right knee (c) junction space area of right knee

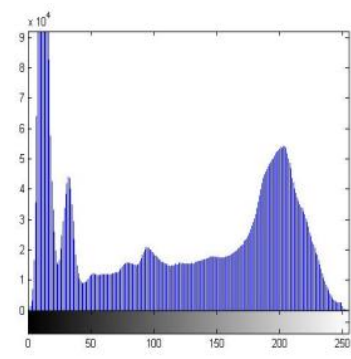

(a)

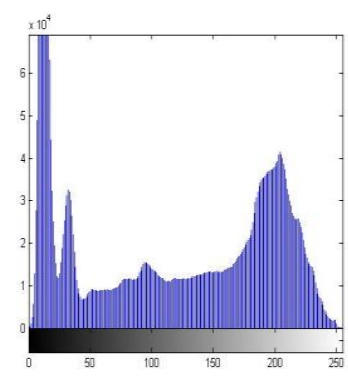

(b)
Figure 9. Comparison (a) histogram of the original radiograph and (b) histogram of the result of the processing

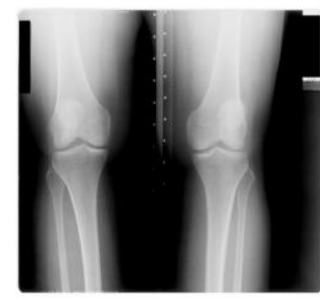

(a)

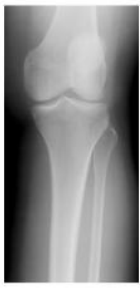

(b)

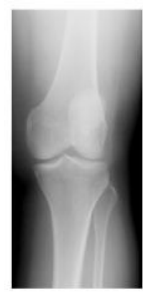

(c)
Figure 11. (a) preprocessed image (b) right knee segmentation (c) left knee segmentation

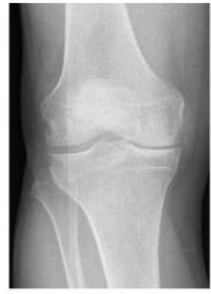

(a)

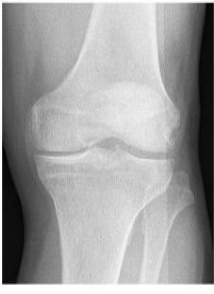

(b)
Figure 13. Segmentation Result (a) right knee and and (b) left knee

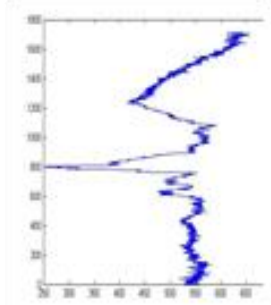

(a)

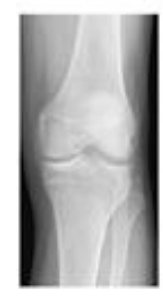

(b)

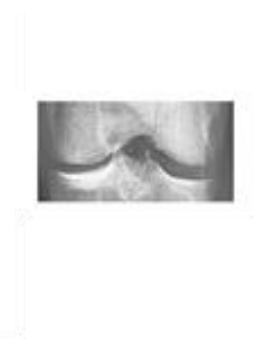

(c)
Figure 15. (a) Row sum graph of left knee (b) left knee and (c) junction space area of left knee

TABLE 1.

SYSTEM'S ACCURACY OF EACH STAGE

\begin{tabular}{|c|c|c|c|}
\hline \multirow[t]{2}{*}{ Experiment } & \multicolumn{2}{|c|}{ Accuracy } & \multirow[t]{2}{*}{$\begin{array}{c}\text { Time } \\
\text { (Seconds) }\end{array}$} \\
\hline & Right Knee (\%) & Left Knee (\%) & \\
\hline 1 & 95,83 & 86,46 & 0,82 \\
\hline 2 & 83,33 & 60,42 & 0,8745 \\
\hline 3 & 89,58 & 83,33 & 0,91 \\
\hline 4 & 100 & 100 & 0,48 \\
\hline
\end{tabular}




\section{REFERENCES}

[1] http://www.wrongdiagnosis.com/o/osteoarthritis/stats-country.html

[2] A. D. Woolf and B. Pfleger "Burden of major musculoskeletal conditions", Bull World Health Organ, vol. 81, pp. 646-656, 2003.

[3] M. J. Elders, "The increasing impact of arthritis on public health," Journal Rheumatol, vol. 60, pp. 6-8, 2000.

[4] J. Martel-Pelletier, D. Lajeunesse, H. Fahmi, G. Tardif, and J. P. Pelletier "New thoughts on the pathophysiology of osteoarthritis: one more step toward new therapeutic targets," Curr Rheumatol Rep, vol. 8, pp. 30-6, 2006.

[5] Buckland-Wright, "Current status of imaging procedures in the diagnosis, prognosis and monitoring of osteoarthritis," Bailliere's Clinical Rheumatology, vol. 11, no. 4, Nov. 1997.

[6] El Miedany, "Altered bone mineral metabolism in patients with osteoarthritis, Éditions scientifiques et médicales Elsevier SAS, 67 :521-7, 2000 .

[7] P. Podsiadlo, M. Wolski, and G. W. Stachowiak, "Automated selection of trabecular bone regions in knee radiographs", Medical Physics, vol. 35, no. 5, pp. 1870-1882, May 2008.

[8] L. Shamir, S. M. Ling, W. W. Scott, A. Bos, and N. Orlov, "Knee X-ray image analysis method for automated detection of Osteoarthritis," IEEE Transactions on Biomedical Engineering, 2008, pp. $1-10$

[9] T. L. Mengko, R. G. Wachjudi, A. B. Suksmono, and Q. Danudirdjo, "Automated Detection of Unimpaired joint space for knee osteoarthritis assessment", 0-7803 -8940-9/050 IEEE, pp. 400-403, 2005

[10] http://oai.epi-ucsf.org/datarelease/
[11] Osteoarthritis Initiative: A Knee Health Study, "Radiographic Procedure Manual for Examinations of the Knee, Hand, Pelvis and Lower Limbs", OAI, San Frasisco, 2006.

[12] http://radonc.ucsf.edu/research_group/jpouliot/tutorial/HU/Lesson 7.html

[13] R.C. Gonzalez and R.E. Woods, Digital image processing, 1992.

[14] D. Cavouras, "An Efficient Clahe-Based, Spot-Adaptive, Image Segmentation Technique for Improving Microarray Genes' Quantification," presented at $2^{\text {nd }}$ International Conference on Experiments /Process/System Modelling/Simulation \& Optimization 2nd IC-EpsMsO Athens, 4-7 July, 2007.

[15] J. E. Barnes "Characteristics and control of contrast in CT. RadioGraphics" vol. 12. 1992, pp. 825-837.

[16] R. C. Gonzalez, R. E. Woods, and S. L. Eddins, Digital image processing using matlab, Pearson Education, 2005.

[17] Mori, Optical Character Recognition, John Willey and Son Canada, 1999.

[18] M. Mehta and R. Sanchati, and A. Marchya, "Automatic Cheque Processing System," International Journal of Computer and Electrical Engineering, vol. 2, no. 4, pp. 761-765, August 2010.

[19] J. R. Movellan, "Tutorial on Gabor Filters", 2008.

[20] Nixon, Feature Extraction and Image Processing $2^{\text {nd }} e d$, Elsevier, 2008

[21] V. P. Vishwakarma, S. Pandey, and M. N. Gupta, "Adaptive Histogram Equalization and Logarithm Transform with Rescaled Low Frequency DCT Coefficients for Illumination Normalization," International Journal of Recent Trends in Engineering, vol 1, no. 1, pp. 318-322, May 2009. 